\title{
The Role of Nrf2 Signaling in PPAR $\beta / \delta$-Mediated Vascular Protection against Hyperglycemia-Induced Oxidative Stress
}

\author{
Rosario Jimenez $\mathbb{D}^{1,}{ }^{1,2,3}$ Marta Toral, ${ }^{1}$ Manuel Gómez-Guzmán $\mathbb{D}^{1},{ }^{1}$ Miguel Romero, ${ }^{1,2}$ \\ Manuel Sanchez, ${ }^{1,2}$ Ayman M. Mahmoud, ${ }^{4,5,6}$ and Juan Duarte ${ }^{1,2,3}$ \\ ${ }^{1}$ Department of Pharmacology, School of Pharmacy, University of Granada, Granada, Spain \\ ${ }^{2}$ Instituto de Investigación Biosanitaria de Granada (ibs.GRANADA), Granada, Spain \\ ${ }^{3}$ Ciber-Enfermedades Cardiovasculares (CIBERCV), Granada, Spain \\ ${ }^{4}$ Physiology Division, Department of Zoology, Faculty of Science, Beni-Suef University, Beni Suef, Egypt \\ ${ }^{5}$ Department of Endocrinology, Diabetes and Nutrition, Charité-University Medicine Berlin, Berlin, Germany \\ ${ }^{6}$ Department of Endocrinology, Diabetes and Nutrition at the Center for Cardiovascular Research (CCR), Charité-University \\ Medicine Berlin, Berlin, Germany \\ Correspondence should be addressed to Rosario Jimenez; rjmoleon@ugr.es
}

Received 23 January 2018; Accepted 18 February 2018; Published 25 June 2018

Academic Editor: Simona Bungau

Copyright (C) 2018 Rosario Jimenez et al. This is an open access article distributed under the Creative Commons Attribution License, which permits unrestricted use, distribution, and reproduction in any medium, provided the original work is properly cited.

\begin{abstract}
Hyperglycemia induces oxidative stress and plays a substantial role in the progression of vascular diseases. Here, we demonstrated the potentiality of peroxisome proliferator-activated receptor (PPAR) $\beta / \delta$ activation in attenuating high glucose-induced oxidative stress in endothelial cells and diabetic rats, pointing to the involvement of nuclear factor erythroid 2-related factor 2 (Nrf2). HUVECs exposed to high glucose showed increased levels of reactive oxygen species (ROS) and upregulated NOX-2, NOX-4, Nrf2, and NQO- 1 effects that were significantly reversed by the PPAR $\beta / \delta$ agonists GW0742 and L165041. Both PPAR $\beta / \delta$ agonists, in a concentration-dependent manner, induced transcriptional and protein upregulation of heme oxygenase-1 (HO-1) under low- and high-glucose conditions. All effects of PPAR $\beta / \delta$ agonists were reversed by either pharmacological inhibition or siRNA-based downregulation of PPAR $\beta / \delta$. These in vitro findings were confirmed in diabetic rats treated with GW0742. In conclusion, PPAR $\beta / \delta$ activation confers vascular protection against hyperglycemia-induced oxidative stress by suppressing NOX-2 and NOX-4 expression plus a direct induction of HO-1; with the subsequent downregulation of the Nrf2 pathway. Thus, PPAR $\beta / \delta$ activation could be of interest to prevent the progression of diabetic vascular complications.
\end{abstract}

\section{Introduction}

Uncontrolled hyperglycemia in diabetes is linked to many micro- and macrovascular complications [1]. Several lines of evidence advocate the role of endothelial dysfunction in the development of cardiovascular (CV) disease [2]. Endothelial dysfunction (ED) represents the key early step and the prognostic marker of diabetes-associated vascular complications and is characterized by diminished bioavailability of vasodilators [3]. In hyperglycemia, oxidative stress and elevated levels of reactive oxygen species (ROS) in the vessels are strongly linked to ED [4]. Overproduction of ROS has been reported to result in a wide account of potentially damaging intermediates that damage DNA, proteins, membrane structure, and metabolic activity, thereby causing cellular dysfunction and cell death, which lastly lead to alterations in the balance between prooxidants and antioxidant arising several diseases as an outcome [5].

The nuclear factor erythroid 2-related factor $2(\mathrm{Nrf} 2)$ is a basic leucine zipper protein that suppresses oxidative stress through activating the transcription of multiple defensive and antioxidant genes [6]. In the endothelium, Nrf2 has been reported to be activated via increased ROS generation [7] and multiple studies have demonstrated the effectiveness of $\mathrm{Nrf} 2$ 


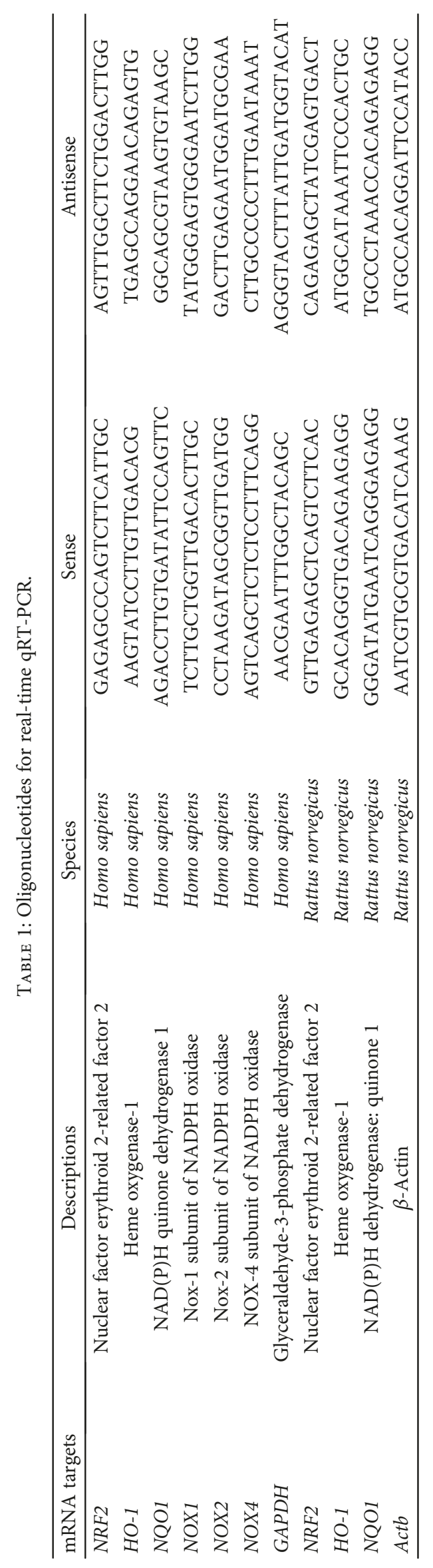



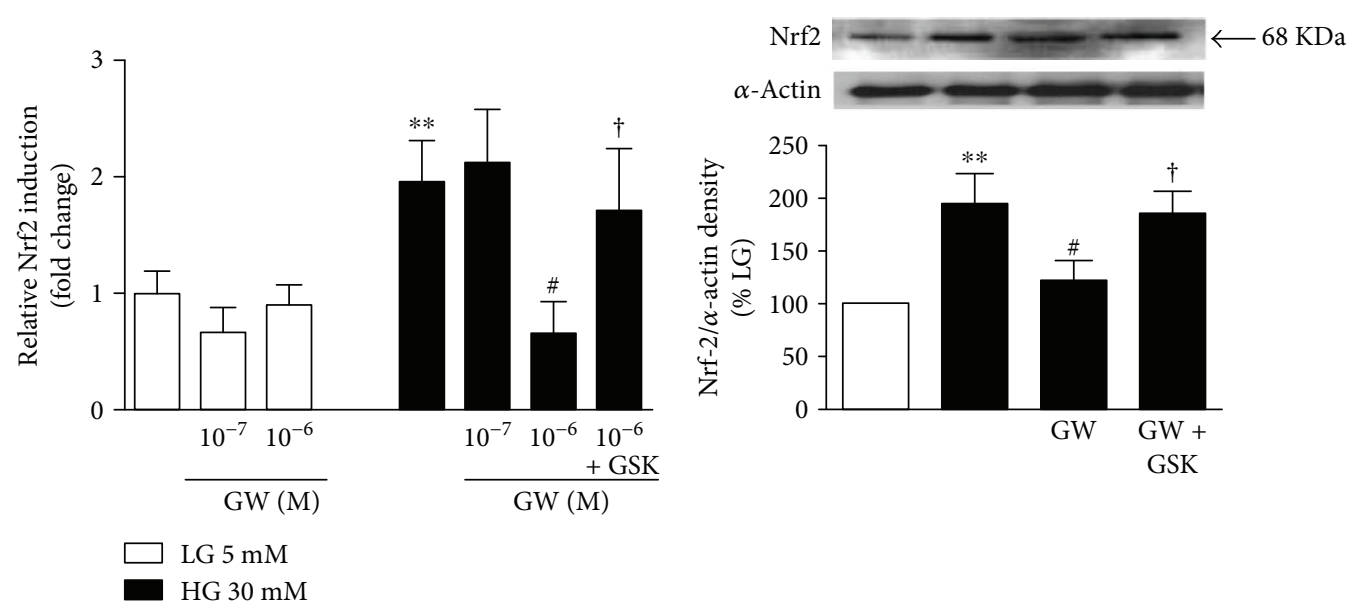

(a)

(b)
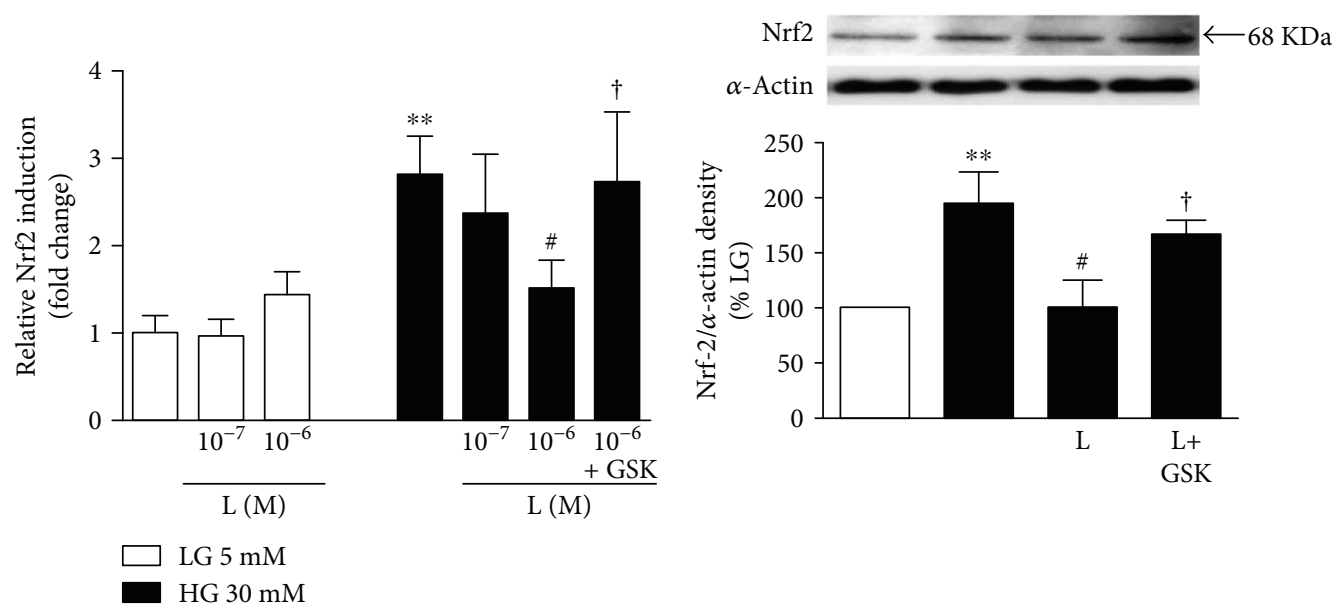

(c)

(d)

FIGURE 1: Effects of PPAR $\beta / \delta$ agonists on Nrf2 expression. $(a, c)$ mRNA and $(b, d)$ protein expression of Nrf2 in HUVECs exposed to low $(5 \mathrm{mM}, \mathrm{LG})$ or high glucose $(30 \mathrm{mM}, \mathrm{HG})$ for $24 \mathrm{~h}$ with or without GW0742 (GW) or L165041 (L) alone or preincubated with the PPAR $\beta / \delta$ antagonist GSK0660 (GSK). mRNA data presented as a ratio of arbitrary units of mRNA $\left(2^{-\Delta \Delta C t}\right)$. All data are mean $\pm \operatorname{SEM}(n=8)$, and experiments were repeated at least three times independently. Protein data presented as densitometric values and protein band normalized to the corresponding $\alpha$-actin; the bands are representative of $n=3-5$. ${ }^{* *} P<0.01$ versus LG. ${ }^{\#} P<0.05$ versus HG. $\dagger P<0.05$ versus L and GW column, respectively.

signaling in counteracting the deleterious repercussion of ROS in the endothelium $[8,9]$.

Peroxisome proliferator-activated receptor- $\beta / \delta(\operatorname{PPAR} \beta / \delta)$ is a member of a group of nuclear receptors that play diverse roles in metabolism, development, and cellular differentiation. $\mathrm{PPAR} \beta / \delta$ regulates numerous genes implicated in glucose homeostasis, and fatty acid metabolism is therefore ubiquitously expressed in metabolically active tissues $[10,11]$. In high-fat diet- (HFD-) induced type 2 diabetes, $\operatorname{PPAR} \beta / \delta$ activation improves glucose and lipid metabolism and confers vascular protection [12]. Previous studies have demonstrated that, independent of their metabolic actions, $\operatorname{PPAR} \beta / \delta$ agonists improved endothelial dysfunction in animal models of diseases associated with increased ROS, such as obesity, diabetes, and hypertension [12-16]. In addition, activation of $\mathrm{PPAR} \beta / \delta$ reestablished the altered insulin signaling pathway in human endothelial cells exposed to high glucose levels [17] and improved vascular reactivity in the arteries of diabetic rodents $[13,14,18]$. Theses endothelium protective effects seem to be mediated via inhibition of mitochondrial- [17] and nicotinamide adenine dinucleotide phosphate (NADPH) oxidase-derived ROS production [14] and ERK1/2 activation [17]. Although PPAR $\beta / \delta$ activation protects the endothelium against diabetes-associated oxidative damage by diminishing the sources of ROS in the vasculature, nothing has yet been reported on the role of Nrf2 signaling in mediating the protective effect of $\operatorname{PPAR} \beta / \delta$. Therefore, we demonstrated the modulatory effect of $\operatorname{PPAR} \beta / \delta$ activation on $\mathrm{Nrf} 2$ and its target genes using in vitro high glucose-induced endothelial cell model and in vivo diabetic animal model.

\section{Materials and Methods}

2.1. Cell Culture and Treatments. Human umbilical vein endothelial cells (HUVECs), isolated from cord veins as 

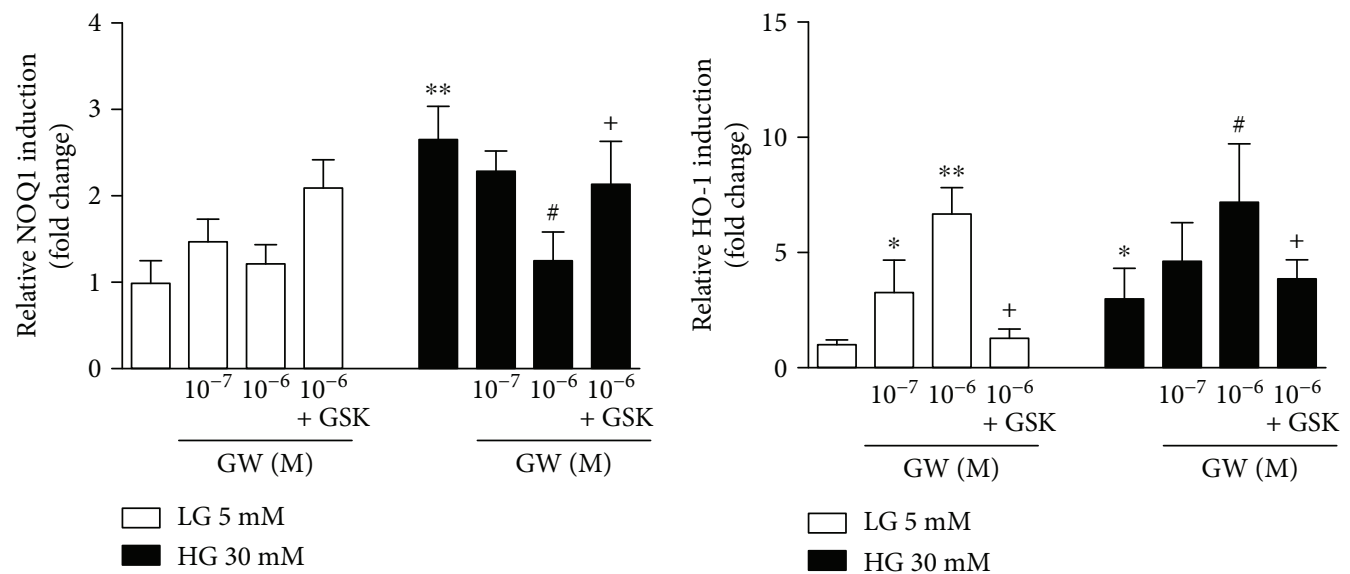

(a)
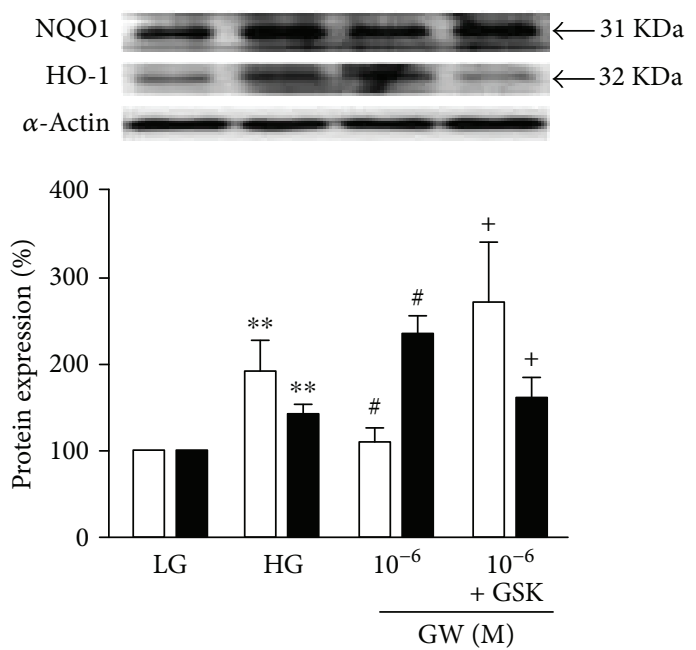

NQO1

HO-1

(c)

Figure 2: Effect of PPAR $\beta / \delta$ agonist, GW0742, on Nrf2 target gene induction. (a, b) mRNA and (c) protein expression of NOQ-1 and HO-1. HUVECs, exposed to low- (LG) or high-glucose (HG) medium for 24 h, were coincubated with GW0742 (GW) alone or preincubated with the GSK0660 (GSK) followed by GW0742. mRNA data presented as a ratio of arbitrary units of mRNA $\left(2^{-\Delta \Delta C t}\right)$. All data are mean \pm SEM $(n=8)$, and experiments were repeated at least three times independently. Protein data presented as densitometric values and protein band normalized to the corresponding $\alpha$-actin; the bands are representative of $n=3-5$. ${ }^{*} P<0.05$ and ${ }^{* *} P<0.01$ versus LG. ${ }^{\#} P<0.05$ versus $\mathrm{HG} .{ }^{+} P<0.05$ versus GW column.

previously reported [14] with some adaptations, were used in all in vitro experiments. The isolated cells were cultured in medium 199 (M199), and cells from passage 2-5 were used for the experiments. Following a $2 \mathrm{~h}$ serum starvation, HUVECs were treated with $10^{-7}-10^{-6} \mathrm{M}$ of either GW0742 or L165041 for $24 \mathrm{~h}$ in low-glucose (LG; $5 \mathrm{mM}$ ) or highglucose $(\mathrm{HG} ; 30 \mathrm{mM})$ condition. Other HUVECs were preincubated with $10^{-6} \mathrm{M}$ GSK0660, PPAR $\beta / \delta$ antagonist, for $1 \mathrm{~h}$ before treatment with the $\operatorname{PPAR} \beta / \delta$ agonists.

2.2. Transfection of $P P A R \beta / \delta$ siRNA. Confluent HUVECs were transfected with PPAR $\beta / \delta$ or control siRNAs (Dharmacon, Lafayette, CO, USA) using Lipofectamine RNAiMAX (Invitrogen, Carlsbad, CA, USA) for $48 \mathrm{~h}$ [19]. The efficiency of PPAR $\beta / \delta$ siRNAs transfection was affirmed using $\mathrm{qPCR}$ and Western blotting.

2.3. Assay of Intracellular ROS. HUVECs were seeded in 96-well plates and treated with $\operatorname{PPAR} \beta / \delta$ agonists and/or antagonist in LG or HG M199 and then incubated with $5 \mu \mathrm{M} \quad 2^{\prime}-7^{\prime}$-dichlorodihydrofluorescein diacetate (CM$\mathrm{H}_{2}$ DCFDA) at $37^{\circ} \mathrm{C}$ for $30 \mathrm{~min}$. After washing, the fluorescence intensity was determined using a microplate reader (Fluorostart, BMG Lab Technologies, Offenburg, Germany).

2.4. Gene Expression Analysis. The effect of PPAR $\beta / \delta$ activation on the expression of $\mathrm{Nrf} 2, \mathrm{NAD}(\mathrm{P}) \mathrm{H}$ quinone dehydrogenase 1 (NQO-1), heme oxygenase-1 (HO-1), NOX-4, NOX-2, and NOX-1 was evaluated using qPCR. Briefly, total 


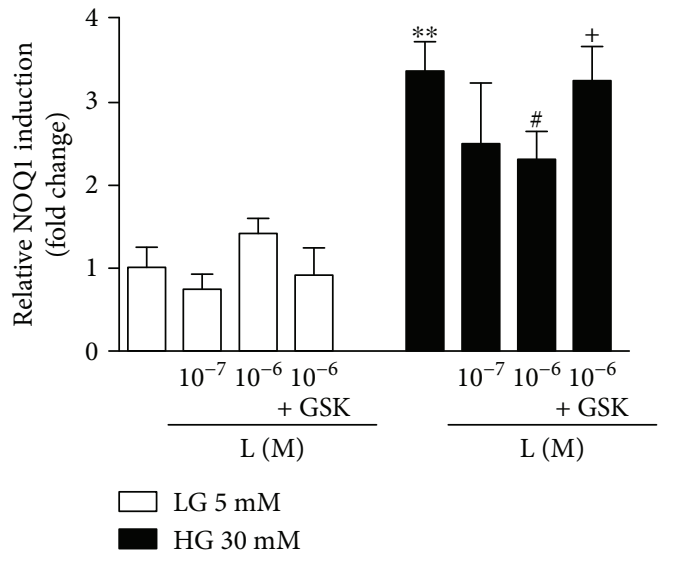

(a)

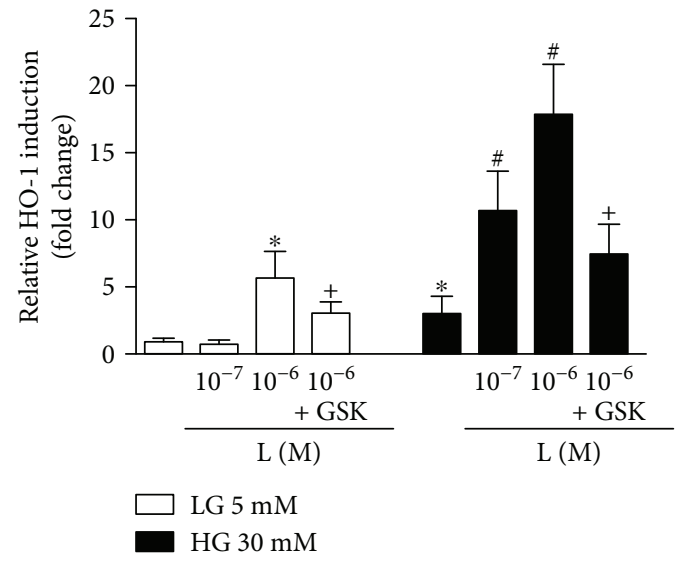

(b)
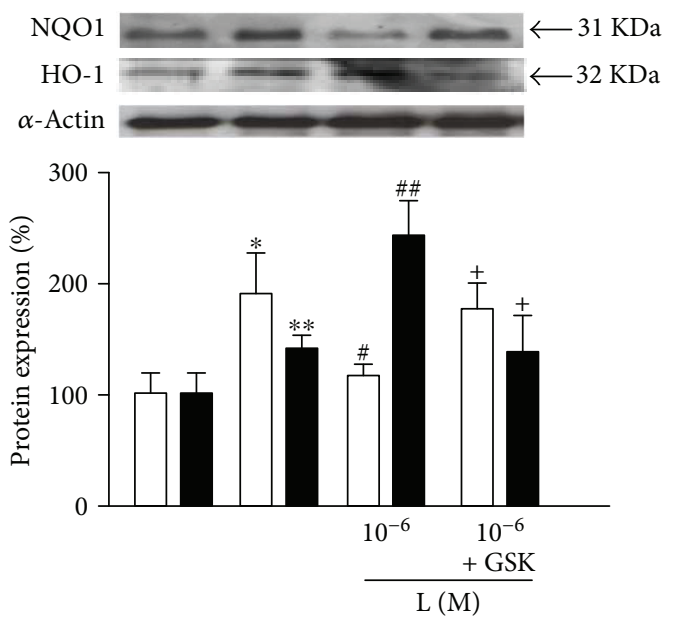

$\square$ NQO1

(c)

Figure 3: Effect of PPAR $\beta / \delta$ agonist, L165041, on Nrf2 target genes. (a, b) mRNA and (c) protein expression of NOQ-1 and HO-1. HUVECs, exposed to low- (LG) or high-glucose (HG) medium for $24 \mathrm{~h}$, were coincubated with L165041 (L) alone or preincubated with the GSK0660 (GSK) followed by L165041. mRNA data presented as a ratio of arbitrary units of mRNA $\left(2^{-\Delta \Delta C t}\right)$. All data are mean \pm SEM $(n=8)$, and experiments were repeated at least three times independently. Protein data presented as densitometric values and protein band normalized to the corresponding $\alpha$-actin; the bands are representative of $n=3-5 .{ }^{*} P<0.05$ and ${ }^{* *} P<0.01$ versus $L G$. ${ }^{\#} P<0.05$ and ${ }^{\# \#} P<0.01$ versus HG. ${ }^{+} P<0.05$ versus $L$ column.

RNA was isolated, quantified, and reverse transcribed into cDNA. qPCR was performed as we previously reported [14], using the primers set described in Table 1 . The obtained data were analyzed using the $2^{-\Delta \Delta \mathrm{Ct}}$ method with $\beta$-actin or GAPDH as housekeeping genes and normalized to the control group.

2.5. Western Blot Analysis. Proteins from HUVECs were separated on SDS-PAGE and transblotted onto PVDF membranes [14, 15]. The blots were probed with antibodies (Santa Cruz Biotechnology, CA, USA) against Nrf2, NQO$1, \mathrm{HO}-1$, and $\alpha$-actin (Santa Cruz Biotechnology, CA, USA) followed by the secondary antibody. The ECL system (Amersham, UK) was used to develop and visualize the blots which were then analysed using Scion Image-Release Beta 4.02 software (http://scion-image.software.informer.com/).
2.6. Animal Experiments. The effect of PPAR $\beta / \delta$ activation on Nrf2 signaling in the aorta was investigated using male Wistar rats weighing $280-320 \mathrm{~g}$ and maintained on a $12 \mathrm{~h}$ light/dark cycle at $24 \pm 1^{\circ} \mathrm{C}$ with standard rat chow water ad libitum. The experimental protocol was approved by the institutional review board of the University of Granada (Spain), and all procedures were conducted according to the guidelines for the Care and Use of Laboratory Animals published by National Institutes of Health. Type 1 diabetes was induced by injection $50 \mathrm{mg}^{-1}$ streptozotocin (STZ) (Sigma-Aldrich) [14] dissolved in a citrate buffer ( $\mathrm{pH} 4.5)$ into the tail vein. Three days after intravenous (i.v.) STZ injection, animals faster for $18 \mathrm{~h}$ were screened using an Accu-Chek Aviva glucometer (Roche Diagnostics S.L., Barcelona, Spain) and rats with blood glucose $200 \mathrm{mg} / \mathrm{dL}^{-1}$ or above were selected. In parallel, control rats received a single 


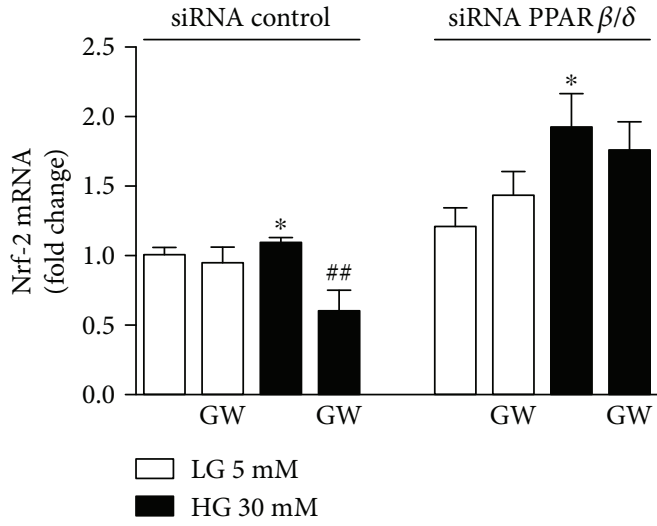

(a)

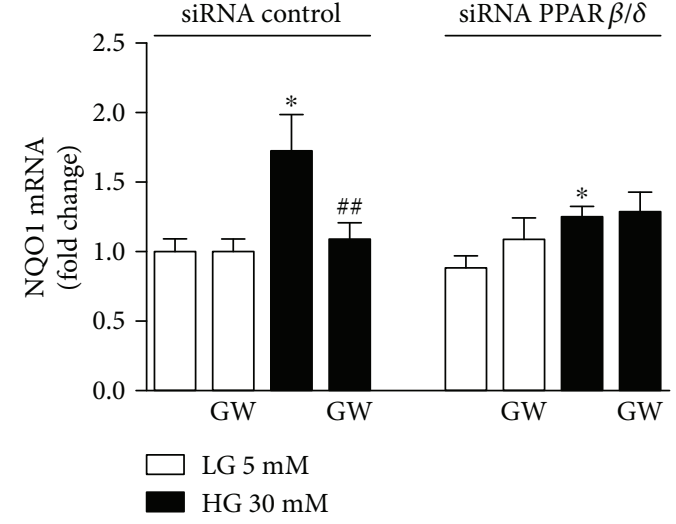

(b)

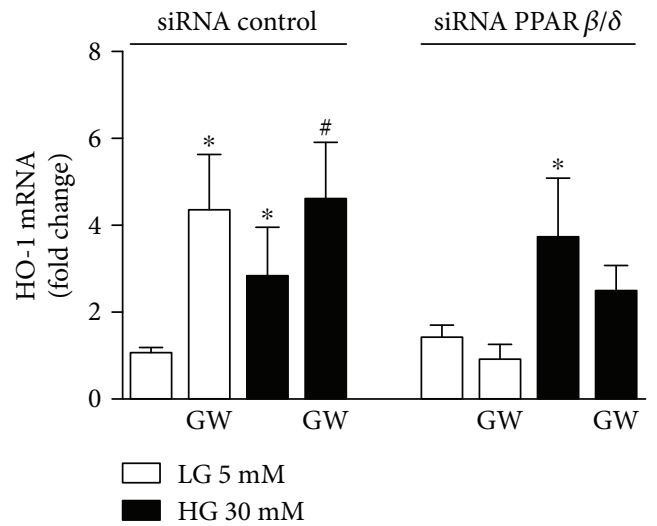

(c)

Figure 4: Role of the PPAR $\beta / \delta$ activation on the Nrf2/ARE pathway. mRNA expression levels of (a) Nrf2, (b) NOQ-1, and (c) HO-1 in control siRNA and siRNA PPAR $\beta / \delta$ cells incubated in low- (LG) or high-glucose (HG) medium for $24 \mathrm{~h}$, in the presence or absence of GW0742 (GW, $\left.10^{-6} \mathrm{M}\right)$. mRNA data presented as a ratio of arbitrary units of mRNA $\left(2^{-\Delta \Delta \mathrm{Ct}}\right)$. All data are mean \pm SEM $(n=8)$, and experiments were repeated at least three times independently. ${ }^{*} P<0.05$ versus $L G$. ${ }^{\#} P<0.01$ and ${ }^{\# \#} P<0.01$ versus HG.

i.v. of citrate buffer. The control and diabetic animals were divided into 4 groups $(N=8-10)$ as follows:

Group I (control): rats received the vehicle 1\% methylcellulose by gavage for 5 weeks.

Group II (GW-treated): rats received $5 \mathrm{mg} / \mathrm{kg} /$ day GW0742 dissolved in $1 \%$ methylcellulose $[20,21]$ by gavage daily for 5 weeks.

Group III (diabetic): diabetic rats received the vehicle 1\% methylcellulose by gavage for 5 weeks.

Group IV (GW-treated diabetic): diabetic rats received $5 \mathrm{mg} / \mathrm{kg} /$ day GW0742 dissolved in $1 \%$ methylcellulose $[20,21]$ by gavage.

At the end of treatments, the rats were sacrificed and dissected and the thoracic aortas were removed. Parts of the aorta were cut into rings which were cryopreserved in $0.1 \mathrm{M}$ PBS plus $30 \%$ sucrose for $1 \mathrm{~h}$, included in OCT medium and kept frozen $-80^{\circ} \mathrm{C}$, while other rings were used to assay NADPH oxidase activity. Other samples of the thoracic aorta were used to isolate RNA, and the gene expression was determined as described above.

2.7. In Situ Detection of Vascular Superoxide Anion Production. The frozen aortic rings were cut into $10 \mu \mathrm{m}$ cross sections by using a cryostat (Microm International Model
HM $500 \mathrm{OM})$. The sections were stained with $10 \mu \mathrm{M}$ dihydroethidium (DHE) for $30 \mathrm{~min}$ in the dark at room temperature followed by counterstaining with DAPI. In the following $24 \mathrm{~h}$, the DHE/DAPI-stained sections were examined using a fluorescence microscope (Leica DM IRB, Wetzlar, Germany) and images were captured. The DHE and DAPI fluorescence was quantified using ImageJ (version 1.32j, http://imagej-1-32j.updatestar.com/). The relative level of superoxide was estimated from the DHE/DAPI fluorescence ratio [22]. The specificity of the assay was tested using the superoxide scavenger tiron.

2.8. Assay of NADPH Oxidase Activity. The activity of NADPH oxidase in thoracic aortic rings of control and diabetic rats was assayed by the lucigenin-enhanced chemiluminescence assay as previously described [14]. Briefly, aortic rings were incubated in HEPES-buffered solution ( $\mathrm{pH} 7.4$ ) to which $100 \mu \mathrm{M}$ NADPH was added. Five $\mu \mathrm{M}$ lucigenin was added, and the luminescence was recorded at $5 \mathrm{sec}$ intervals over a $200 \mathrm{sec}$ using in a luminometer (Lumat LB 9507, Berthold, Germany). After subtracting the basal values, the relative luminescence units (RLU)/min/mg dry tissue was used to express NADPH oxidase activity. 

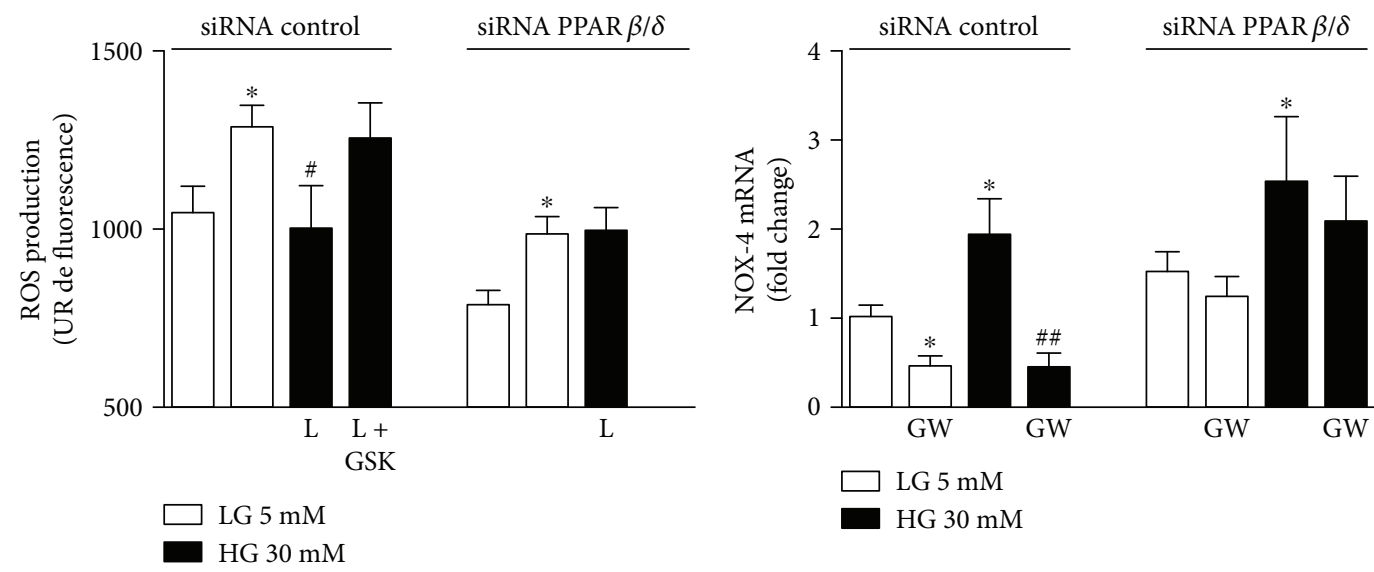

(a)

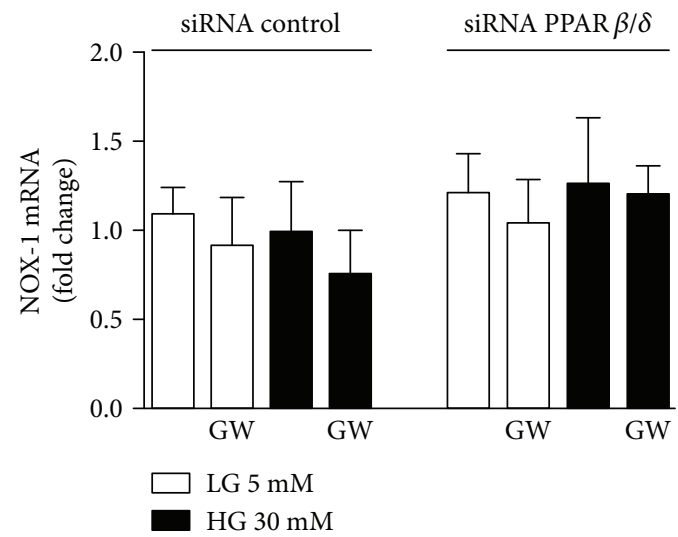

(c)

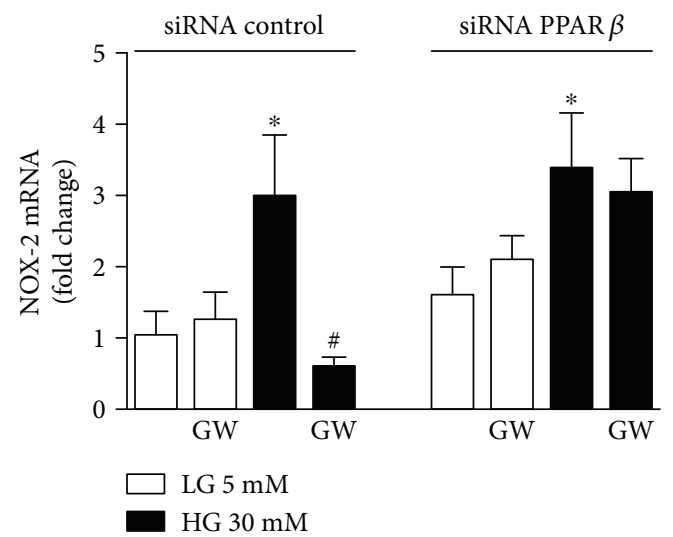

(d)

FIGURE 5: Effect of PPAR $\beta / \delta$ agonists in intracellular ROS production. (a) ROS and (b-d) mRNA expression levels of NOX-4 (b), NOX-1 (c), and NOX-2 (d) in HUVEC transfected with PPAR $\beta / \delta$-specific siRNA (siRNA PPAR $\beta / \delta$ ) incubated in low- (LG) or high-glucose (HG) medium for $24 \mathrm{~h}$ in the presence or absence of either L165041 (L, $\left.10^{-6} \mathrm{M}\right)$ or GW0742 $\left(\mathrm{GW}, 10^{-6} \mathrm{M}\right)$, respectively. GSK0660 (10 $\left.0^{-6} \mathrm{M}\right)$ was added $30 \mathrm{~min}$ before the incubation with L165041. mRNA data presented as a ratio of arbitrary units of mRNA $\left(2^{-\Delta \Delta C t}\right)$. All data are mean \pm SEM $(n=8)$, and experiments were repeated at least three times independently. ${ }^{*} P<0.05$ versus LG. ${ }^{\#} P<0.01$ and ${ }^{\# \#} P<0.01$ versus HG.

2.9. Statistical Analysis. All data were analyzed using GraphPad Prism 5 (GraphPad Software, San Diego, CA, USA). The results were expressed as mean $\pm \mathrm{SEM}$, and comparisons were made using Student's $t$-test or one-way ANOVA followed by Bonferroni's post hoc analysis. A $P$ value $<0.05$ was considered statistically significant.

\section{Results}

3.1. High Glucose Increases Nrf2 and Its Target Genes in HUVECs. HUVECs were incubated in HG medium for $24 \mathrm{~h}$, and the expression of Nrf2, NQO-1, and HO-1 was assayed. HG induced a significant increase in the expression of Nrf2 both mRNA and protein (Figure 1). Similarly, the expression of NQO-1 and HO-1 gene as well as protein was significantly increased in HUVECs exposed to HG medium as compared to the LG one as represented in Figures 2 and 3 , respectively.

3.2. Effects of PPAR $\beta / \delta$ Agonists on High Glucose-Induced Changes in Expression of Nrf2 and Its Target Genes. HUVECs treated with $10^{-7}$ and $10^{-6} \mathrm{M}$ GW0742 (Figure 1(a)) or L165041 (Figure 1(c)) for 24h in LG medium showed nonsignificant changes in the expression levels of Nrf2. On the contrary, coincubation with $\operatorname{PPAR} \beta / \delta$ agonists downregulated Nrf2 mRNA (Figures 1(a) and 1(c)) and protein expression levels (Figures 1(b) and 1(d)) in HG-induced HUVECs. Coincubation of the HUVECs with $10^{-6} \mathrm{M}$ of the PPAR $\beta / \delta$ antagonist GSK0660 inhibited the effects exerted by PPAR $\beta / \delta$ agonists (Figure 1 ).

The PPAR $\beta / \delta$ agonists did not alter the expression of NQO-1 mRNA and protein in normal experimental conditions. However, in HUVECs incubated in high-glucose medium, NQO-1 mRNA and protein levels were decreased by either GW0742 (Figures 2(a) and 2(c)) or L165041 (Figures 3(a) and 3(c)). Coincubation with GSK0660 markedly abolished the effect of PPAR $\beta / \delta$ agonists on NQO- 1 expression, involving $\mathrm{PPAR} \beta / \delta$ activation.

In contrast, in both conditions, the incubation with GW0742 (Figures 2(b) and 2(c)) and L165041 (Figures 3(b) and 3(c)) upregulated the expression of HO-1 an effect that was abolished by coincubation with GSK0660. 


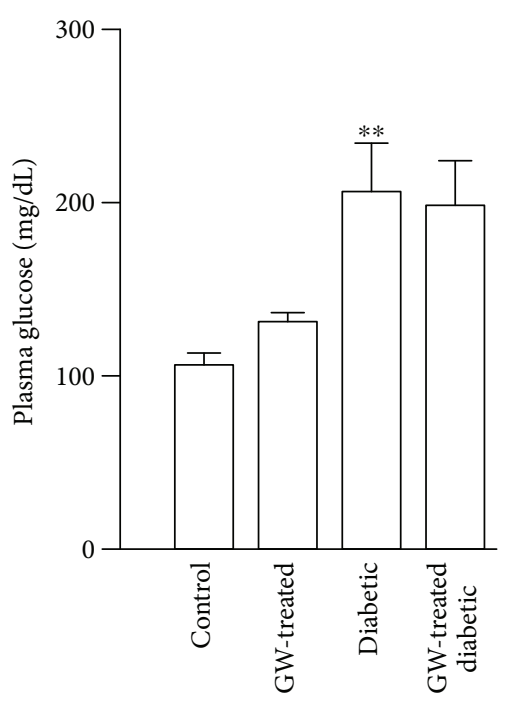

FIGURE 6: Effect of GW0742 on blood glucose levels of control and diabetic rats. Plasma glucose concentrations were measured by colorimetric method. Values are expressed as mean \pm SEM of $n=8$ -10 rats. ${ }^{* *} P<0.01$, diabetic versus control rats.

$\operatorname{PPAR} \beta / \delta$-induced downregulation of $\mathrm{Nrf} 2$ signaling was confirmed by siRNA-based downregulation of PPAR $\beta / \delta$. HUVECs transfected with $\operatorname{PPAR} \beta / \delta$-specific siRNA showed a marked suppression of GW0742-induced upregulation of Nrf2 (Figure 4(a)) and NQO-1 (Figure 4(b)) under highglucose condition, while the expression of HO-1 was abolished in both conditions (Figure 4(c)).

3.3. Effects of $P P A R \beta / \delta$ Agonists on Intracellular ROS Production. Oxidative stress induced by hyperglycemia has been reported in endothelial cells [20]. Accordingly, we observed higher levels of ROS induced by $30 \mathrm{mM}$ of glucose compared with baseline conditions (5 mM glucose) (Figure 5(a)). The PPAR $\beta / \delta$ agonist L165041 $\left(10^{-6} \mathrm{M}\right)$ abolished ROS production under the high-glucose condition, indicating its protective potential at the level of reactive species generation. Furthermore, coincubation of this $\operatorname{PPAR} \beta / \delta$ agonist with GSK0660 or PPAR $\beta / \delta$-specific siRNA suppressed its efficacy to inhibit high glucose-induced ROS overproduction (Figure 5(a)).

HUVECs, under high-glucose condition, showed markedly upregulated mRNA abundance of NOX-4 (Figure 5(b)) and NOX-2 (Figure 5(d)) while the expression of NOX-1 was not significantly affected (Figure 5(c)).

In experimental low-glucose condition, the coincubation of HUVECs with GW0742 downregulated the mRNA abundance of NOX-4 (Figure 5(b)); this NOX-4 downregulation seems to be linked with the capacity to elevate in both gene and protein expressions of HO- 1 expression as a gene target of $\mathrm{PPAR} \beta / \delta$. Interestingly, the potential of GW0742 to inhibit the increase of mRNA abundance of NOX-4 and NOX-2 induced by high glucose was blunted by the siRNA-mediated downregulation of $\operatorname{PPAR} \beta / \delta$ (Figures 5(b) and 5(d)).
3.4. Effect of GW0742 on Blood Glucose Levels of Control and Diabetic Rats. STZ diabetic rats showed hyperglycemia evidenced by the significantly elevated levels of fasting blood glucose as compared to the control group. In both experimental groups, the long-term GW0742 administration did not alter the levels of glucose (Figure 6), indicating that the protective effect of $\operatorname{PPAR} \beta / \delta$ agonist was glucose-independent.

3.5. Effects of Oral GW0742 on Nrf2 Pathway in Aorta of Diabetic Rats. Aortas from STZ diabetic rats showed a marked increase in Nrf2 (Figure 7(a)), NQO-1 (Figure 7(b)), and HO-1 (Figure 7(c)) mRNA expression as compared to the control rats. Chronic treatment with GW0742 downregulated Nrf2 and NQO-1 in the aortas of diabetic rats while it showed no effect on normal rat aorta. However, similar to the in vitro results, HO-1 mRNA abundance was higher in the vascular wall of control- and diabetic-treated rats (Figure $7(\mathrm{c})$ ).

3.6. GW0742 Decreases Vascular ROS and NADPH Oxidase Activity. To evaluate the effect of GW0742 on hyperglycemia-provoked oxidative stress, aortic rings from all experimental groups were stained with DHE and the activity of NADPH oxidase was determined. DHE staining revealed increased superoxide levels in the aorta of diabetic rats as depicted in Figures $8(\mathrm{a})$ and $8(\mathrm{~b})$. In the same context, the aorta of diabetic rats showed significantly increased activity of NADPH oxidase (Figure 8(c)). While exerting no effect in normal rats, GW0742 suppressed ROS levels and NADPH oxidase in the aorta of STZ diabetic rats.

\section{Discussion}

Oxidative stress is a leading cause of ED and has previously been implicated in $\mathrm{CV}$ complications in diabetes [4]. Herein, we provide the first evidence that $\operatorname{PPAR} \beta / \delta$ agonists can indirectly downregulate the Nrf2 pathway by suppressing HG-induced ROS accumulation in the vascular wall. Given the role of ROS in vascular diseases, our study suggests a potential therapeutic role of $\mathrm{PPAR} \beta / \delta$ in diabetic vascular complications.

The role of hyperglycemia in diabetes vasculopathy has been well-acknowledged. Although the vascular endothelium has adaptive mechanisms to counteract hyperglycemiainduced oxidative stress, superfluous ROS levels induce endothelial dysfunction. In endothelial cells, increased superoxide generation represents the hallmark of hyperglycemiamediated oxidative stress [23]. Accordingly, HUVECs exposed to HG and aorta of STZ diabetic rats showed markedly elevated levels of ROS. These findings are explained by the increased activity of NADPH oxidase which represents a major source of superoxide production under hyperglycemic conditions $[17,24]$. Here, HUVECs showed increased NOX-4 expression following exposure to HG levels. NOX-4 is the prominent and major subunit of NADPH oxidase that provokes the generation of superoxide anions in the endothelium $[25,26]$. Therefore, NOX-4 can induce oxidative damage [27] and endothelial injury [28] in response to cellular 


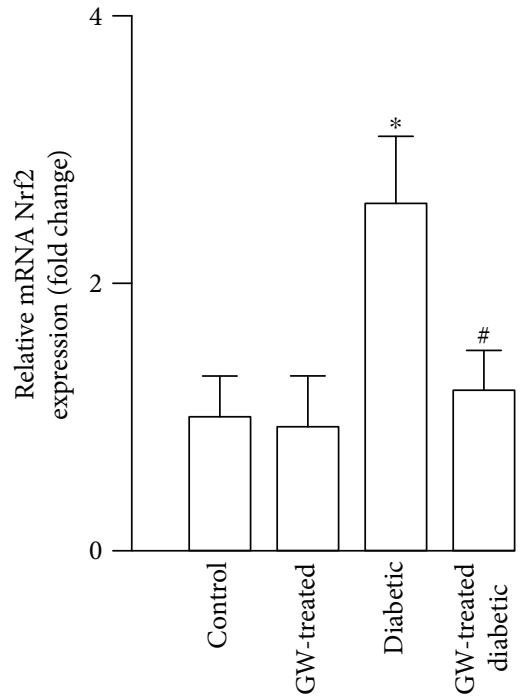

(a)

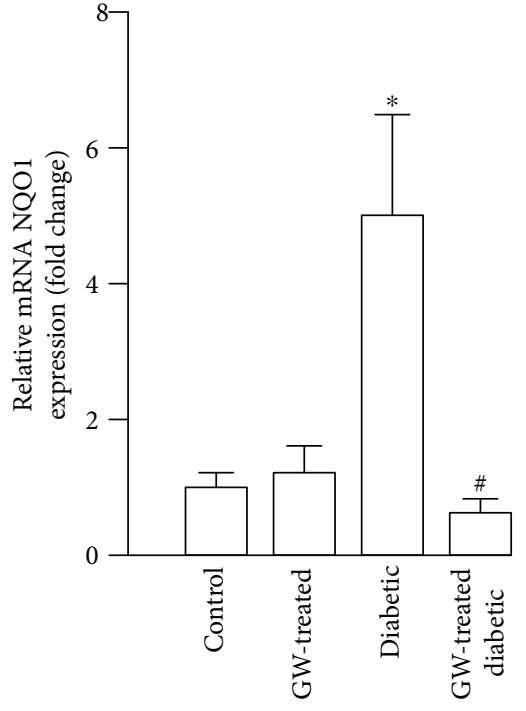

(b)

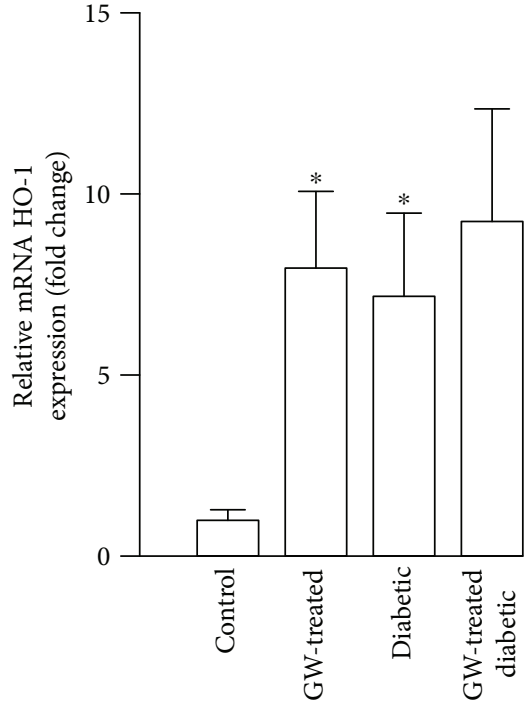

(c)

FIGURE 7: Effect of oral GW0742 on the Nrf2 pathway in the aorta of diabetic rats. mRNA expression of (a) Nrf2, (b) NQO-1, and (c) HO-1 in the aorta of all experimental groups. Data are presented as the ratio of arbitrary units of mRNA $\left(2^{-\Delta \Delta \mathrm{Ct}}\right)$. Results are shown as mean \pm SEM $n=8-10$ rats. ${ }^{*} P<0.05$, diabetic versus control group. ${ }^{\#} P<0.05$, GW0472-treated diabetic versus nontreated diabetic rats.

stress. Previous studies have also demonstrated increased NADPH oxidase in diabetic animals $[9,26]$ and human patients [29]. In addition, the increased levels of ROS could be attributed to hyperglycemia-induced eNOS uncoupling and mitochondrial electron transport chain as previously demonstrated [30-32]. Interestingly, a functional NOX-4 has been reported to be present in the mitochondria [33]. In a preparation of pure mitochondria, knockdown of NOX-4 by siRNA blocked mitochondrial superoxide generation induced by glucose [33]. Moreover, experimental evidence showed that genetic knockdown or inhibition of NOX-4 reduces ROS production in the vascular endothelium $[27,34]$. Along with the upregulated NOX-4, HG-induced HUVECs showed increased expression of NOX-2, a NADPH oxidase subunit known to be expressed in a significant amount in HUVECs as well as in rat aortic endothelium [26].

GW0742 suppressed NADPH oxidase activity and NOX4 induction and prevented oxidative stress, indicating that the antioxidative action of PPAR $\beta / \delta$ activation was related to its suppressive effect on NOX-4 activation induced by HG levels. Since both pharmacological inhibition and knockdown of $\operatorname{PPAR} \beta / \delta$ abolished the suppressive effect of GW0742 on NOX expression and ROS generation, our results point to the specific inhibitory role of $\operatorname{PPAR} \beta / \delta$ activation on HG-induced oxidative stress. These findings were confirmed in vivo where the treatment with GW0742 abolished superoxide generation and reduced NADPH oxidase in the aorta of STZ diabetic rats. Therefore, the PPAR $\beta / \delta$ induced suppression of NOX-4 can significantly improve the integrity and prevent injury of the vasculature in diabetes. Accordingly, results from experimental animal models of STZ- and HFD-induced diabetes treated with GW0742 $[12,14]$ add support to our findings. Through its ability to activate $\mathrm{PPAR} \beta / \delta$, GW0742 significantly suppressed $\mathrm{NADPH}$ oxidase activity as well as the expression of its subunits, p47phox and p22phox, leading to reduced levels of superoxide in the diabetic aorta $[12,14]$.

The chronic administration of PPAR $\beta / \delta$ agonist did not reduce blood glucose levels in STZ diabetic rats, indicating that its beneficial vascular effects are independent of the glycemic state. Hence, we investigated the possible role of Nrf2/ARE/antioxidant signaling. In diabetes, activation of Nrf2 is an adaptive mechanism that protects the endothelium. This notion is being supported by several in vitro and in vivo studies. In bovine aortic endothelial cells, activation of Nrf2 pathway represented a defense mechanism against oxidative damage induced by advanced glycation end products [35] and hyperglycemia [32]. Consistent findings were elucidated by Ungvari et al. [20] in coronary endothelial cells where the adaptive induction of Nrf2 protected against the deleterious effects of hyperglycemia. In $\mathrm{Nrf2}\left({ }^{+/+}\right)$mice, HFD feeding elicited increased expression of HO-1 mRNA but not in $\mathrm{Nrf} 2\left(^{-/-}\right)$mice [20]. In addition, HFD-fed $\mathrm{Nrf2}\left(^{-/-}\right)$mice showed increased vascular ROS levels and diminished vascular reactivity when compared with the $\mathrm{Nrf2}\left({ }^{+/+}\right)$mice received the same HFD, confirming the role of $\mathrm{Nrf} 2$ as an adaptive mechanism to counteract diabetes-associated endothelial dysfunction [20]. In our in vitro hyperglycemia model, HUVECs exhibited upregulated gene and protein expression of Nrf2 along with increased expression of NQO-1 and HO-1, adding support to the previous findings. Similarly, diabetic rats showed upregulated aortic Nrf2, NQO-1, and HO-1. In conjunction with the activated Nrf2 signaling, the aorta of the diabetic rats exhibited increased superoxide levels and NADPH oxidase activity. ROS produced by NOX activity can activate Nrf2 [36, 37] and hence NOX provides a feedback defense mechanism counteracting oxidative stress [38]. In the same context, Brewer et al. [39] demonstrated that NOX-4 has a potential role 


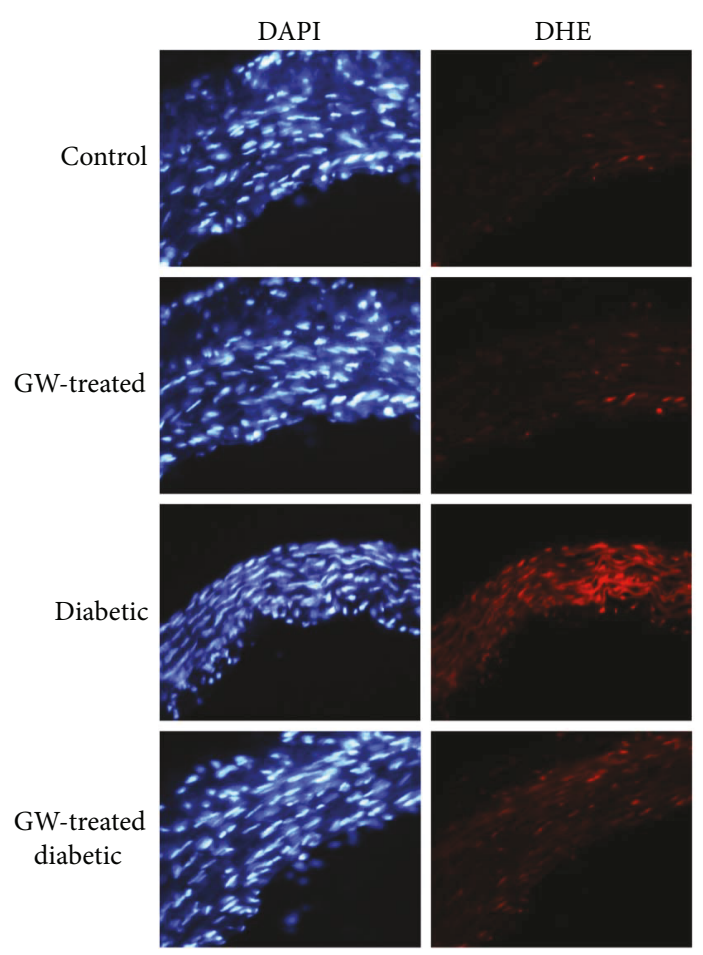

(a)

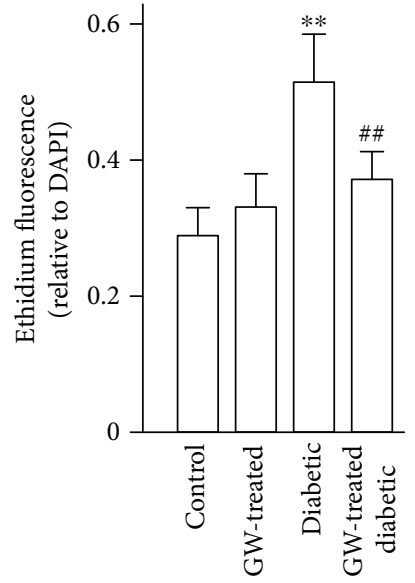

(b)

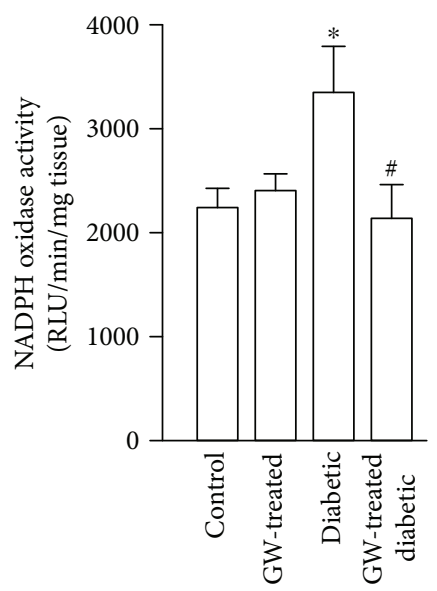

(c)

FIGURE 8: GW0742 decreases vascular ROS and NADPH oxidase activity. (a) The left panel shows blue fluorescence of the nuclear stain DAPI $(\times 400$ magnification), and the right panel shows arteries incubated in the presence of DHE which produces a red fluorescence when oxidized to ethidium by ROS. (b) Averaged values, mean \pm SEM ( $n=8-10$ rings from different rats), of the red ethidium fluorescence normalized to the blue DAPI fluorescence. (c) NADPH oxidase activity measured by lucigenin-enhanced chemiluminescence $(n=6-10)$. ${ }^{*} P<0.05$ and ${ }^{* *} P<0.01$, diabetic versus control group. ${ }^{\#} P<0.05$ and ${ }^{\# \#} P<0.01$, GW0472-treated diabetic versus nontreated diabetic rats.

in regulating the redox status in cardiomyocytes in vivo via activating the Nrf2 pathway.

In our in vitro and in vivo models of hyperglycemia, PPAR $\beta / \delta$ activation significantly reduced Nrf2 and NQO- 1 expression, whereas upregulating HO- 1 . These results corroborate the findings of Ali et al. [40], who explored the role of HO-1 in mediating the vasculoprotective efficacy of
$\operatorname{PPAR} \beta / \delta$ and its coactivator PGC1 $\alpha$ against oxidantinduced injury. It can thus be suggested that $\operatorname{PPAR} \beta / \delta$ agonists induce HO-1 independently of the Nrf2-pathway. HO1 has been suggested as a protective factor against vascular oxidative stress and inflammation [41], and polymorphism of its gene promotor is associated with vascular diseases $[41,42]$. Therefore, GW0742-induced upregulation of HO- 
1 observed herein contributed to the antioxidant potential of $\operatorname{PPAR} \beta / \delta$. In addition, the declined activity of NADPH oxidase via $\operatorname{PPAR} \beta / \delta$ activation in our experimental models may be linked to the downregulation of Nrf2 and NQO-1. GW0742 has exerted a marked effect on the expression HO- 1 as compared to L-165041. This is explained by the fact that GW0742 is a high-affinity $\mathrm{PPAR} \beta / \delta$ agonist while L165041 is a nonselective agonist.

In conclusion, this study shows, for the first time, that $\operatorname{PPAR} \beta / \delta$ activation confers vascular protection against oxidative stress in diabetes via direct induction of $\mathrm{HO}-1$ and downregulation of NOX-4 and, to a lesser extent, NOX-2. Additionally, the results show that, independent of the glycemic state, activation of PPAR $\beta / \delta$ diminished ROS levels, NADPH oxidase activity, and expression of Nrf2 and NQO-1. This research highlights the potential of PPAR $\beta / \delta$ agonists as novel therapies to reduce vascular complications of diabetes.

\section{Conflicts of Interest}

The authors declare that there are no conflicts of interest regarding the publication of this paper.

\section{Acknowledgments}

This work was supported by Grants from Ministerio de Economía y Competitividad and Fondo Europeo de Desarrollo Regional (FEDER) (SAF2010-22066-C02-01, SAF2010-22066-C02-02, SAF2011-28150, SAF2014-55523$\mathrm{R})$, Junta de Andalucía (Proyecto de excelencia, P12-CTS2722), and Instituto de Salud Carlos III (RIC RD12/0042/ 0011), Spain.

\section{References}

[1] M. Brownlee, "Biochemistry and molecular cell biology of diabetic complications," Nature, vol. 414, no. 6865, pp. 813-820, 2001.

[2] B. Chen, Y. Lu, Y. Chen, and J. Cheng, "The role of Nrf2 in oxidative stress-induced endothelial injuries," The Journal of Endocrinology, vol. 225, no. 3, pp. R83-R99, 2015.

[3] A. Lerman and J. C. Burnett Jr., "Intact and altered endothelium in regulation of vasomotion," Circulation, vol. 86, no. 6 , Supplement, pp. III12-III19, 1992.

[4] T. Fiorentino, A. Prioletta, P. Zuo, and F. Folli, "Hyperglycemia-induced oxidative stress and its role in diabetes mellitus related cardiovascular diseases," Current Pharmaceutical Design, vol. 19, no. 32, pp. 5695-5703, 2013.

[5] M. Valko, D. Leibfritz, J. Moncol, M. T. D. Cronin, M. Mazur, and J. Telser, "Free radicals and antioxidants in normal physiological functions and human disease," The International Journal of Biochemistry \& Cell Biology, vol. 39, no. 1, pp. 4484, 2007.

[6] S. Satta, A. M. Mahmoud, F. L. Wilkinson, M. Yvonne Alexander, and S. J. White, "The role of Nrf2 in cardiovascular function and disease," Oxidative Medicine and Cellular Longevity, vol. 2017, Article ID 9237263, 18 pages, 2017.

[7] X. L. Chen, S. E. Varner, A. S. Rao et al., "Laminar flow induction of antioxidant response element-mediated genes in endothelial cells. A novel anti-inflammatory mechanism," Journal of Biological Chemistry, vol. 278, no. 2, pp. 703-711, 2003.

[8] A. M. Mahmoud, F. L. Wilkinson, E. M. McCarthy et al., "Endothelial microparticles prevent lipid-induced endothelial damage via Akt/eNOS signaling and reduced oxidative stress," The FASEB Journal, vol. 31, no. 10, pp. 4636-4648, 2017.

[9] A. M. Mahmoud, F. L. Wilkinson, A. M. Jones et al., "A novel role for small molecule glycomimetics in the protection against lipid-induced endothelial dysfunction: involvement of Akt/ eNOS and Nrf2/ARE signaling," Biochimica et Biophysica Acta (BBA) - General Subjects, vol. 1861, no. 1, pp. 3311-3322, 2017.

[10] P. A. Grimaldi, "Regulatory role of peroxisome proliferatoractivated receptor delta (PPAR $\delta)$ in muscle metabolism. A new target for metabolic syndrome treatment?," Biochimie, vol. 87, no. 1, pp. 5-8, 2005.

[11] S. Takahashi, T. Tanaka, and J. Sakai, "New therapeutic target for metabolic syndrome: PPAR $\delta$," Endocrine Journal, vol. 54, no. 3, pp. 347-357, 2007.

[12] M. Toral, M. Gómez-Guzmán, R. Jiménez et al., "Chronic peroxisome proliferator-activated receptor $\beta / \delta$ agonist GW0742 prevents hypertension, vascular inflammatory and oxidative status, and endothelial dysfunction in dietinduced obesity," Journal of Hypertension, vol. 33, no. 9, pp. 1831-1844, 2015

[13] M. Toral, M. Romero, R. Jiménez et al., "Carnitine palmitoyltransferase- 1 up-regulation by PPAR- $\beta / \delta$ prevents lipid-induced endothelial dysfunction," Clinical Science, vol. 129, no. 9, pp. 823-837, 2015.

[14] A. M. Quintela, R. Jiménez, M. Gómez-Guzmán et al., “Activation of peroxisome proliferator-activated receptor- $\beta /-\delta$ $(\operatorname{PPAR} \beta / \delta)$ prevents endothelial dysfunction in type 1 diabetic rats," Free Radical Biology \& Medicine, vol. 53, no. 4, pp. 730741, 2012.

[15] M. J. Zarzuelo, R. Jimenez, P. Galindo et al., "Antihypertensive effects of peroxisome proliferator-activated receptor- $\beta$ activation in spontaneously hypertensive rats," Hypertension, vol. 58, no. 4, pp. 733-743, 2011.

[16] M. J. Zarzuelo, M. Gómez-Guzmán, R. Jiménez et al., "Effects of peroxisome proliferator-activated receptor- $\beta$ activation in endothelin-dependent hypertension," Cardiovascular Research, vol. 99, no. 4, pp. 622-631, 2013.

[17] A. M. Quintela, R. Jiménez, L. Piqueras et al., "PPAR $\beta$ activation restores the high glucose-induced impairment of insulin signalling in endothelial cells," British Journal of Pharmacology, vol. 171, no. 12, pp. 3089-3102, 2014.

[18] X. Y. Tian, W. T. Wong, N. Wang et al., "PPAR $\delta$ activation protects endothelial function in diabetic mice," Diabetes, vol. 61, no. 12, pp. 3285-3293, 2012.

[19] L. Piqueras, M. J. Sanz, M. Perretti et al., “Activation of $\operatorname{PPAR} \beta / \delta$ inhibits leukocyte recruitment, cell adhesion molecule expression, and chemokine release," Journal of Leukocyte Biology, vol. 86, no. 1, pp. 115-122, 2009.

[20] Z. Ungvari, L. Bailey-Downs, T. Gautam et al., "Adaptive induction of NF-E2-related factor-2-driven antioxidant genes in endothelial cells in response to hyperglycemia," American Journal of Physiology-Heart and Circulatory Physiology, vol. 300, no. 4, pp. H1133-H1140, 2011.

[21] D. Morales-Cano, L. Moreno, B. Barreira et al., "Activation of $\operatorname{PPAR} \beta / \delta$ prevents hyperglycaemia-induced impairment of $\mathrm{Kv} 7$ channels and cAMP-mediated relaxation in rat coronary 
arteries," Clinical Science, vol. 130, no. 20, pp. 1823-1836, 2016.

[22] R. Jiménez, R. López-Sepúlveda, M. Kadmiri et al., "Polyphenols restore endothelial function in DOCA-salt hypertension: role of endothelin-1 and NADPH oxidase," Free Radical Biology \& Medicine, vol. 43, no. 3, pp. 462-473, 2007.

[23] S. Karbach, T. Jansen, S. Horke et al., "Hyperglycemia and oxidative stress in cultured endothelial cells - a comparison of primary endothelial cells with an immortalized endothelial cell line," Journal of Diabetes and its Complications, vol. 26, no. 3, pp. 155-162, 2012.

[24] B. Lassegue, A. San Martin, and K. K. Griendling, "Biochemistry, physiology, and pathophysiology of NADPH oxidases in the cardiovascular system," Circulation Research, vol. 110, no. 10, pp. 1364-1390, 2012.

[25] A. Konior, A. Schramm, M. Czesnikiewicz-Guzik, and T. J. Guzik, "NADPH oxidases in vascular pathology," Antioxidants \& Redox Signaling, vol. 20, no. 17, pp. 2794-2814, 2014.

[26] T. Ago, T. Kitazono, H. Ooboshi et al., "Nox4 as the major catalytic component of an endothelial NAD(P)H oxidase," Circulation, vol. 109, no. 2, pp. 227-233, 2004.

[27] A. E. Vendrov, K. C. Vendrov, A. Smith et al., "NOX4 NADPH oxidase-dependent mitochondrial oxidative stress in agingassociated cardiovascular disease," Antioxidants \& Redox Signaling, vol. 23, no. 18, pp. 1389-1409, 2015.

[28] J. Kim, M. Seo, S. K. Kim, and Y. S. Bae, "Flagellin-induced NADPH oxidase 4 activation is involved in atherosclerosis," Scientific Reports, vol. 6, no. 1, article 25437, 2016.

[29] T. J. Guzik, S. Mussa, D. Gastaldi et al., "Mechanisms of increased vascular superoxide production in human diabetes mellitus: role of $\mathrm{NAD}(\mathrm{P}) \mathrm{H}$ oxidase and endothelial nitric oxide synthase," Circulation, vol. 105, no. 14, pp. 1656-1662, 2002.

[30] T. Nishikawa and E. Araki, "Impact of mitochondrial ROS production in the pathogenesis of diabetes mellitus and its complications," Antioxidants \& Redox Signaling, vol. 9, no. 3, pp. 343-353, 2007.

[31] M. Hoshiyama, B. Li, J. Yao, T. Harada, T. Morioka, and T. Oite, "Effect of high glucose on nitric oxide production and endothelial nitric oxide synthase protein expression in human glomerular endothelial cells," Nephron Experimental Nephrology, vol. 95, no. 2, pp. e62-e68, 2003.

[32] M. He, M. Nitti, S. Piras et al., "Heme oxygenase-1-derived bilirubin protects endothelial cells against high glucose-induced damage," Free Radical Biology \& Medicine, vol. 89, pp. 9198, 2015.

[33] K. Block, Y. Gorin, and H. E. Abboud, "Subcellular localization of Nox4 and regulation in diabetes," Proceedings of the National Academy of Sciences of the United States of America, vol. 106, no. 34, pp. 14385-14390, 2009.

[34] S. Basuroy, S. Bhattacharya, C. W. Leffler, and H. Parfenova, "Nox4 NADPH oxidase mediates oxidative stress and apoptosis caused by TNF- $\alpha$ in cerebral vascular endothelial cells," American Journal of Physiology-Cell Physiology, vol. 296, no. 3, pp. C422-C432, 2009.

[35] M. He, R. C. M. Siow, D. Sugden, L. Gao, X. Cheng, and G. E. Mann, "Induction of HO-1 and redox signaling in endothelial cells by advanced glycation end products: a role for Nrf2 in vascular protection in diabetes," Nutrition, Metabolism, \& Cardiovascular Diseases, vol. 21, no. 4, pp. 277-285, 2011.

[36] I. T. Lee, S. W. Wang, C. W. Lee et al., "Lipoteichoic acid induces HO-1 expression via the TLR2/MyD88/c-Src/
NADPH oxidase pathway and Nrf2 in human tracheal smooth muscle cells," Journal of Immunology, vol. 181, no. 7, pp. 50985110, 2008.

[37] S. Papaiahgari, Q. Zhang, S. R. Kleeberger, H. Y. Cho, and S. P. Reddy, "Hyperoxia stimulates an Nrf2-ARE transcriptional response via ROS-EGFR-PI3K-Akt/ERK MAP kinase signaling in pulmonary epithelial cells," Antioxidants \& Redox Signaling, vol. 8, no. 1-2, pp. 43-52, 2006.

[38] L. Gao and G. E. Mann, "Vascular NAD(P)H oxidase activation in diabetes: a double-edged sword in redox signalling," Cardiovascular Research, vol. 82, no. 1, pp. 9-20, 2009.

[39] A. C. Brewer, T. V. A. Murray, M. Arno et al., "Nox4 regulates Nrf2 and glutathione redox in cardiomyocytes in vivo," Free Radical Biology \& Medicine, vol. 51, no. 1, pp. 205-215, 2011.

[40] F. Ali, N. S. Ali, A. Bauer et al., "PPAR $\delta$ and PGC1 $\alpha$ act cooperatively to induce haem oxygenase- 1 and enhance vascular endothelial cell resistance to stress," Cardiovascular Research, vol. 85, no. 4, pp. 701-710, 2010.

[41] M. Exner, E. Minar, O. Wagner, and M. Schillinger, "The role of heme oxygenase-1 promoter polymorphisms in human disease," Free Radical Biology \& Medicine, vol. 37, no. 8, pp. 1097-1104, 2004.

[42] M. Schillinger, M. Exner, W. Mlekusch et al., "Heme oxygenase-1 gene promoter polymorphism is associated with abdominal aortic aneurysm," Thrombosis Research, vol. 106, no. 2, pp. 131-136, 2002. 


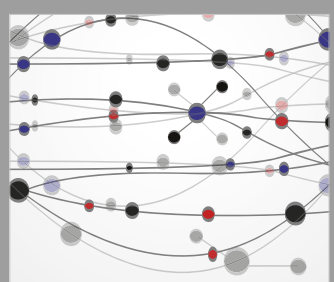

The Scientific World Journal
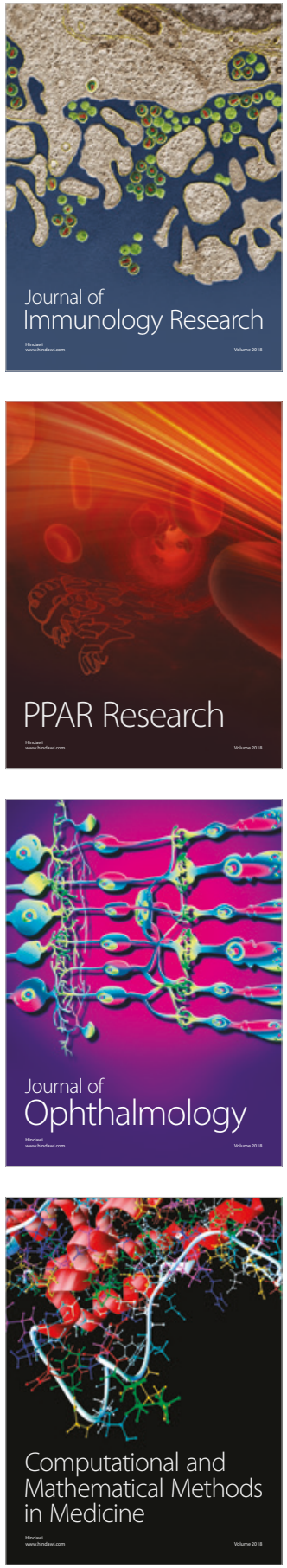

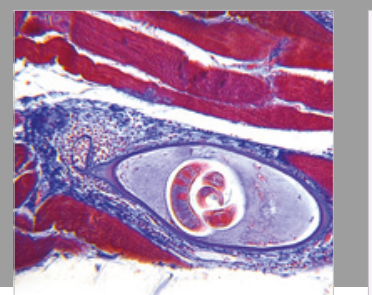

Gastroenterology Research and Practice

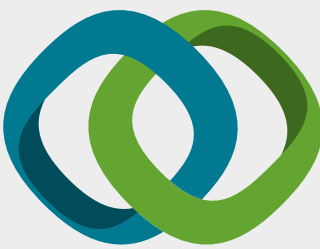

\section{Hindawi}

Submit your manuscripts at

www.hindawi.com
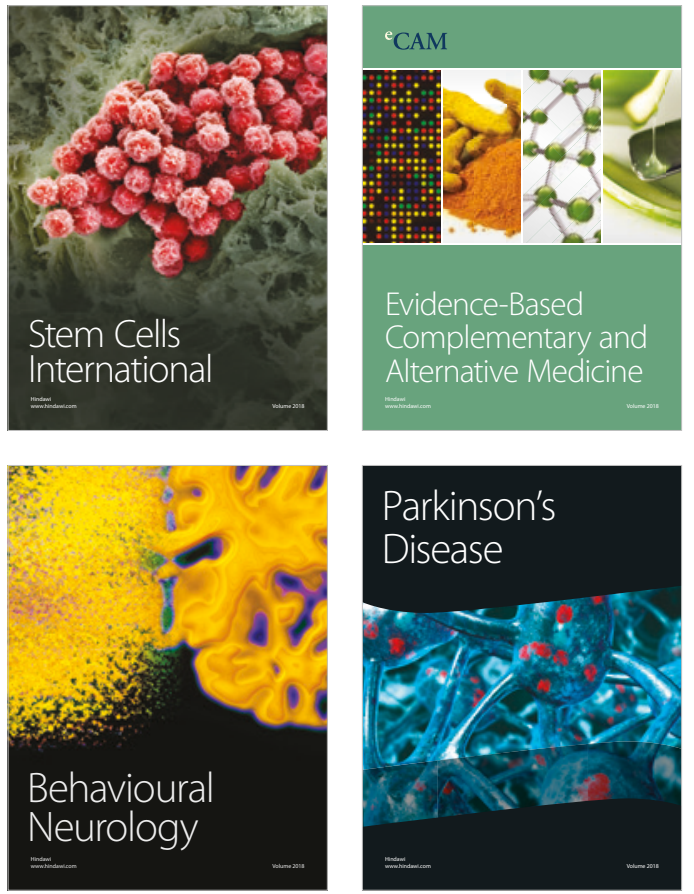

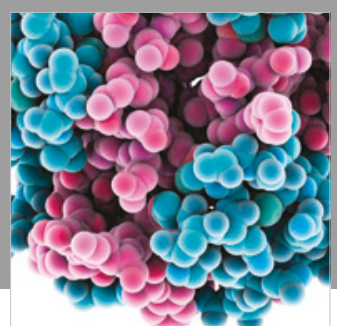

ournal of

Diabetes Research

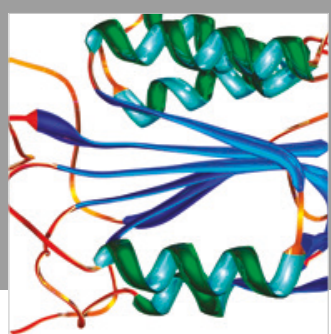

Disease Markers
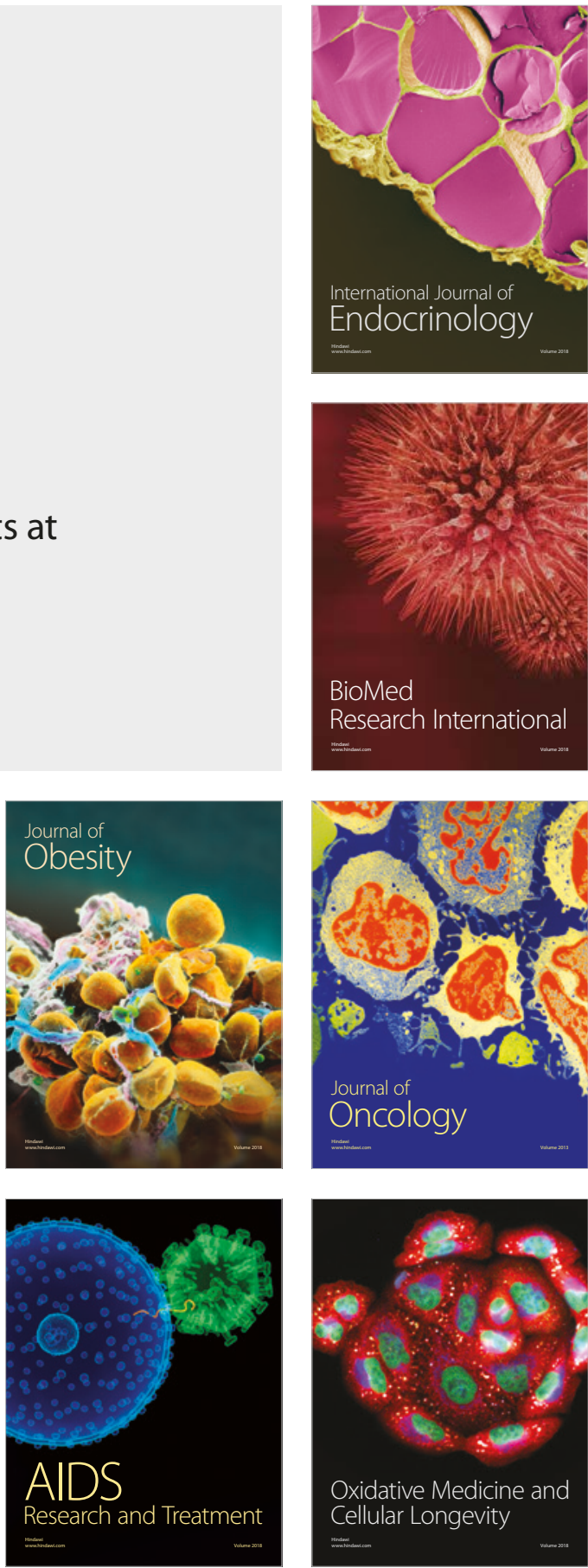